\title{
O uso de fantoches e suas contribuições para a narrativa de crianças
}

\section{The use of puppets and their contributions to children's narrative}

https://doi.org/10.34112/2317-0972a2021V39n83p83-103

Marcela A. Moreira Araujo ${ }^{1}$

Maria Silvia Pinto de Moura Librandi da Rocha²

RESUMO: Este artigo aborda parte dos resultados de pesquisa desenvolvida em uma turma de Educação Infantil de uma escola privada, visando estudar possíveis contribuições do uso de fantoches para a construção de narrativas por crianças. Desenvolvida em 2017, a pesquisa foi composta por um conjunto de procedimentos metodológicos, dos quais destacamos dez encontros com a turma estudada ( 19 crianças entre 3 e 4 anos) e sua professora. As análises do material empírico permitiram evidenciar que os fantoches, além de aumentarem a motivação das crianças para recontarem as histórias, afetaram, positivamente, a estrutura das narrativas: as crianças usam-nos para sustentar os enredos; criam e incluem mais personagens; experimentam diferentes vozes; constroem diálogos entre personagens e/ou atribuem características psicológicas a eles. Com este estudo, pretende-se contribuir para reflexões sobre a importância da construção de práticas pedagógicas diferenciadas relacionadas à literatura infantil e seus efeitos sobre o desenvolvimento das crianças.

PALAVRAS-CHAVE: Educação Infantil; prática-pedagógica; literatura infantil.

ABStRAct: This article discusses the results of the research developed during Early Childhood Education classes in a private school, with the object to study the possible

1. Pontifícia Universidade Católica de Campinas, Campinas, SP, Brasil

2. Pontifícia Universidade Católica de Campinas, Campinas, SP, Brasil 
contributions of the use of puppets, on the construction of narratives made by children. Developed in 2017, the research consisted of a set of methodological procedures, in which, we highlight, ten meetings with the teacher and the group of students participating in the study (19 children between 3 and 4 years old). The analyzes, allowed us to identify that the puppets increases children's motivation to recount stories, positively and affected the structure of the narratives: the children used them to support the plots; They created and included more characters; They experienced different voices; built dialogues between characters and/or attributed psychological characteristics to them. We hope that these results contribute on the reflections of the importance, the construction of differentiated pedagogical practices related to children's literature and its effects on children's development. KEYWORDS: Nursery education; practical-pedagogical; children's literature.

\section{A literatura E AS NARRATIVAS COMO MEDIADORES DO DESENVOLVIMENTO} HUMANO

Para Vigotski (2009, p. 333), “o bom ensino é aquele que conduz o desenvolvimento, atuando sobre aquilo que ainda não está formado na criança: o ensino deve fazer o desenvolvimento avançar". Ou seja, "o ensino seria totalmente desnecessário se pudesse utilizar apenas o que já está maduro no desenvolvimento, se ele mesmo não fosse fonte de desenvolvimento e surgimento do novo" (VIGOTSKI, 2009, p. 334).

$\mathrm{O}$ ensino que promove desenvolvimento é aquele que possibilita ao sujeito situar-se em uma esfera mais ampla das relações sociais, expandindo seus horizontes, trazendo-lhe algo novo. Dependendo da qualidade das mediações proporcionadas à criança, do ambiente em que ela vive, da cultura local, entre outros fatores, o seu desenvolvimento se dará de uma maneira ou de outra, através da concretização da aprendizagem.

Levando em consideração que o ensino e a aprendizagem são processos distintos, porém dependentes um do outro, inter-relacionados, podemos ressaltar que a qualidade do ensino interfere diretamente na condução da aprendizagem. Vigotski (2012) nos apresenta a seguinte reflexão:

[...] aprendizagem não é, em si mesma, desenvolvimento, mas uma correta organização da aprendizagem conduz ao desenvolvimento mental, ativa todo um grupo de processos de desenvolvimento, e esta ativação não poderia produzir-se sem a aprendizagem. Por isso, a aprendizagem é um momento intrinsecamente necessário 
e universal para que se desenvolvam na criança essas características humanas não-naturais, mas formadas historicamente (p.115).

A perspectiva histórico-cultural se contrapõe radicalmente a uma visão puramente biológica do desenvolvimento infantil, levando em consideração que não é possível compreendê-lo como um processo natural, que se desenrola de forma espontânea. A constatação de que as funções psicológicas que o educador pretende desenvolver devem ser requeridas por atividades em que esteja colocada, em alguma medida, a intencionalidade, evidencia que não basta expor as turmas com as quais se trabalha aos objetos da cultura; para além disso, é preciso dizer o que esses objetos são, atribuir-lhes sentido. Por isso é importante contar histórias, trabalhar com literatura; é uma maneira de construir significados, de possibilitar que esses significados sejam apropriados.

Existem várias maneiras de se promover atividades que demandam o desenvolvimento das funções psíquicas das crianças, como, por exemplo, as brincadeiras de faz de conta, o uso de fantoches, a leitura de livros infantis, a produção conjunta de narrativas... Certamente, cada uma dessas atividades tem especificidades em termos de características estruturais, modos de funcionamento e formas de envolvimento das crianças; ouvir histórias não é o mesmo que contá-las e também não é o mesmo que dramatizá-las. Embora em nenhuma dessas atividades a criança se encontre em posição passiva, de mera receptora, posto que interpreta, ressignifica, realça e secundariza certos pontos das narrativas de modos singulares, de fato há diferenças em termos de seu funcionamento psíquico quando acompanha uma narrativa já estruturada, ouvindo-a, e quando ela própria vai tecendo, ponto a ponto, uma história. E como, por princípio, a variabilidade de atividades oferecidas às crianças repercute na criação de múltiplas vias de desenvolvimento, é importante que todas estejam presentes no cotidiano infantil.

Entre essas formas, a literatura é uma produção cultural de grande porte e tem uma relação robusta com a constituição do sujeito. Pensando nisso, buscamos verificar o que tem sido dito sobre a importância da literatura infantil.

Para iniciar nossa discussão, trazemos Mortatti (2014, p. 31):

[...] os (bons) textos literários encantam e ensinam (obviamente, se lidos, ou pelo menos ouvidos), porque fazem diferença em nossas vidas, constituem experiências profundamente humanas [...], porque nos ajudam a formular perguntas para nossa vida, estimulam nossa sabedoria, nossa busca de conhecimento de nós mesmos e do mundo. Nesse sentido, encantam e ensinam, porque, lendo-os, aprendemos algo sobre 
nossa vida, ao mesmo tempo em que aprendemos sobre a importância da literatura na formação do ser humano [...] Esses textos têm, portanto, uma função formativa específica.

A autora cita três sentidos complementares entre si, propiciados pelo bom ensino literário nas escolas. $\mathrm{O}$ primeiro é o fato de que a literatura educa e ensina. $\mathrm{O}$ segundo é que a literatura é um meio para a modificação/transformação humana e o terceiro é que a literatura é, por si só, objeto de ensino para a educação literária e para a formação de bons leitores. Ela ressalta que aos professores não-leitores falta a vivência da fruição estética. Sendo assim, fica muito difícil convencer seus alunos sobre a importância da literatura com palavras vazias.

Assim como Mortatti, Abrantes (2013) também ressalta que para a formação de novos leitores os adultos desempenham papel crucial:

O livro infantil como objeto social que socializa a linguagem literária para a criança se apresenta inicialmente como relação da criança com a cultura escrita, a qual passa necessariamente pela mediação do adulto. A criança lê o texto com a voz emprestada do adulto e, portanto, os conteúdos literários a que a criança tem acesso ocorrem inicialmente em decorrência da relação do adulto com o livro infantil (ABRANTES, 2013, p. 164).

Abrantes (2011) afirma que a utilização de livros infantis na sala de aula estimula os processos imaginativos da criança, promovendo a possibilidade de ampliação das suas experiências e assimilação de conteúdos. O livro na sala de aula pode ativar processos de pensamento, devido à necessidade gerada na criança de apropriação do enunciado da história. "A criança pode compreender, pela vivência das relações sociais, que as histórias a que tem acesso são ativadas pela singular relação do adulto com o objeto social livro" (ABRANTES, 2011, p. 52).

Em sua tese, o autor defende o seguinte:

A Literatura objetivada em livros destinados à criança é mediação imprescindível das atividades sistematizadas na educação infantil, considerada tanto em seu conteúdo, quanto na forma de relação que se estabelece com as crianças. O livro infantil, como objeto social, tem como possibilidade revelar para a criança de cinco a seis anos, na medida de sua realização nas relações sociais, objetos e acontecimentos em seus aspectos essenciais, apresentando movimentos e contradições inerentes à prática social a partir 
de uma abordagem imaginativa que transforma idealmente a realidade, articulando-se como relação teórica frente ao real (2011, p. 57 e 58).

Já Silva \& Urt (2016, p. 231) destacam que a literatura "possibilita à criança o impulso a uma universalização cultural e, a partir da socialização, ela pode tornar-se capaz de imaginar e criar novas formas de se relacionar com o mundo que a cerca - é a universalização do saber!”. De acordo com as autoras, "por meio da prática da leitura a criança é inserida no mundo da cultura escrita e, além de apropriações no mundo cultural, informativo e cognitivo, estabelece relações com o outro e com o grupo" (p. 235).

Para elas, a literatura na Educação Infantil pode ser utilizada como um mecanismo que auxilia e promove o processo de aprendizagem, quando provoca nas crianças questionamentos e inquietações, permitindo que estabeleçam relações com os conceitos elaborados socialmente. Os livros infantis podem servir de mecanismo para a formação e a transformação humana, ao possibilitar o entendimento da realidade e o movimento do processo dinâmico social.

Machado (2017) aponta que a literatura infantil pode estimular múltiplas possibilidades e novas vivências que alimentam a memória das crianças, desenvolvem a imaginação, estimulam o ato criativo e a construção de saberes sociais. A leitura de livros infantis, efetuada inicialmente pelas mãos e voz do professor, pode ser um grande incentivo para que a criança adquira gosto pela leitura desde cedo e o primeiro passo para que procure pelos livros; pode, até mesmo, ser um incentivo para que comece a produzir narrativas. A partir daí, é possível promover momentos na sala de aula em que as próprias crianças sejam as leitoras das histórias, de modo que elas se apropriem do livro, utilizando-o "como um instrumento mediador para a criação de sua história, e que os momentos de leitura, feitos por elas ou por seus colegas, sejam de fruição de texto, momentos de prazer com potencialidades para o aprimoramento de diversas funções em desenvolvimento." (MACHADO, 2017, p. 55).

De acordo com Costa, Ramos \& Panozzo (2007), a literatura é uma arte que não deveria entrar na sala de aula carregando o peso dos conteúdos programáticos, mas sim a leveza do prazer e do encantamento que uma obra literária pode trazer. A mudança na educação literária poderá ocorrer quando "a criança tiver voz para falar da obra e de si, para falar de suas expectativas, para falar de suas impressões, para trocar com o professor e com os colegas aquilo que gostou e também aquilo que rejeitou, enfim, para viver a obra, o faz-de-conta, o possível veiculado na ficção" (COSTA; RAMOS; PANOZZO, 2007, p. 138). Para os autores, 
A escola de educação infantil, sendo instituição de formação de sujeitos, deveria explorar o universo simbólico, da palavra e da imagem. E isso só será possível se, em cada contato com o livro, a criança puder ver além da palavra, além da visualidade. A obra acontece quando o leitor percebe que tem nas mãos a capacidade de ver, de criar, de construir, de participar do texto como coautor, criando sentido àquilo que não é estanque e pronto, mas sugerido e inacabado (p. 138).

Geraldi (2006) aponta a necessidade de trazer para dentro da escola o prazer pela leitura, a partir do resgate de alguns princípios da nossa vivência de leitores. $\mathrm{O}$ respeito à caminhada do leitor é o primeiro deles e se manifesta em duas direções: a seleção dos livros adotados para leitura e a incondicionalidade de que o leitor possa abandonar a leitura de um livro que não lhe agrada. O segundo princípio é permitir a leitura livre, feita por indicação de colegas, pela curiosidade, pela capa, pelo título. Junto a este indica-se a necessidade de repensar a avaliação como uma revisão do processo. $\mathrm{O}$ último princípio é o de que a quantidade pode gerar qualidade, pela possibilidade de novas experiências através do contato com o texto.

Todas as formas de leitura possuem sua relevância, mas, buscando promover o prazer pela leitura, o contato com a literatura infantil precisa ser mais valorizado nas escolas. A realização de atividades que propiciem às crianças colocar em funcionamento a linguagem oral, a memória e a imaginação, e que ofereçam a elas a oportunidade de construírem suas próprias narrativas, contribuem ricamente para o seu desenvolvimento.

Bruner (1991) aponta que os seres humanos organizam suas experiências e sua memória principalmente de forma narrativa, sendo que, para o autor, o indivíduo, ao narrar, constrói realidades e constitui a sua mente. É comum as crianças terem contato com narrativas desde cedo, seja através dos livros infantis, de relatos de experiências, da apropriação da cultura. É a partir dessas experiências que as crianças começam a produzir narrativas, juntamente com o processo de apropriação da linguagem. Vale ressaltar que quando a criança produz suas primeiras narrativas, é comum que sejam sem sentido ou incoerentes para o ouvinte, embora façam sentido para ela. É importante destacar que a habilidade narrativa é uma conquista da prática social, fomentando a capacidade humana de narrar e partilhar histórias, como forma de dar sentido à realidade.

O objetivo que definimos para nossa pesquisa foi estudar possíveis contribuições do uso de fantoches para a construção de narrativas por crianças, sustentadas pelo 
trabalho com livros de histórias. Esse é um tema ainda pouco explorado por investigações científicas, como pudemos constatar em pesquisa no Portal de Periódicos Capes, com o descritor "Literatura Infantil "'. Selecionamos para análises os artigos em português, revisados por pares e publicados no período de 2009 a 2019.

Foram encontrados um total 242 trabalhos. Entre eles, elegemos os que envolviam a participação ativa de crianças nas pesquisas e passamos de 242 para 25 trabalhos selecionados, o que demonstra que apenas $10 \%$ das pesquisas envolveram efetivamente as crianças (de 3 a 12 anos) como participantes. A leitura dos resumos nos permitiu constatar que apenas um deles (KIRCHOF; SILVEIRA, 2009) menciona o uso de fantoches relacionado à contação de histórias; porém, não especifica exatamente como são utilizados, nem quais efeitos podem ser decorrentes dessa prática, porque o foco do trabalho em questão era outro (falaremos sobre isso a seguir). Ou seja, filtrando apenas os trabalhos que envolvem a literatura infantil, participação de crianças e o uso de fantoches, não encontramos nenhum resultado.

O trabalho acima mencionado (KIRCHOF; SILVEIRA, 2009) merece ser comentado, pois nele são analisados 140 episódios de contação de histórias, registrados por alunas do curso de Pedagogia, entre os anos de 2005 e 2007. Do material empírico apresentado, interessa-nos destacar dois pontos: primeiramente, que dos 140 relatos, em apenas 40 (ou seja, $28 \%$ ) a contação incluía material de apoio (como o avental com figuras nele coladas, fantasias, varal de gravuras, bonecos de materiais variados, flanelógrafos e fantoches); em segundo lugar, as análises feitas pelos autores evidenciam que, com ou sem material de apoio nos episódios, predomina, fortemente, o que tem sido chamado de pedagogização da literatura. Esse termo é usado como referência a ações pedagógicas que reduzem a dimensão poética, imaginativa e transgressora que a literatura possui, para usá-la como instrumento para ensinar algo relativo a conteúdos escolares e/ou a bons modos e comportamentos morais.

Em síntese, a revisão de literatura nos permite argumentar que os resultados de nossa pesquisa têm originalidade, considerando-se que tem sido pouco explorado o uso de recursos semióticos concretos (como é o caso dos fantoches) complementares aos próprios livros de histórias infantis, como materialidades que contribuem para a construção de narrativas e imersão no mundo da literatura.

3. A pesquisa bibliográfica foi feita, inicialmente, em 2017 e atualizada em 2019. 
MÉTodo

O material exposto a seguir foi construído a partir de 10 encontros, feitos com 19 crianças entre 3 e 4 anos ( 13 meninos e 6 meninas). A seleção da escola se deu pela proximidade e pelo bom relacionamento que a pesquisadora já tinha com a instituição, porque seu filho frequentava uma turma (diferente da pesquisada), e pelo interesse por compreender melhor como a escola trabalhava com os fantoches (levando em consideração que seu filho já havia levado um para casa e tentado contar uma história sobre ele). A turma escolhida foi a referente ao último ano dessa unidade escolar. Antes do início da pesquisa, foram realizadas reuniões com a diretora, com o coordenador pedagógico e com a professora para apresentar o projeto e definir como seriam os encontros. Após a aprovação da escola e do Comitê de Ética as crianças foram convidadas a participar da pesquisa e as autorizações enviadas aos pais. Participaram dos encontros somente as que foram autorizadas pelos pais, com a devida assinatura nos Termos de Consentimento Livre e Esclarecido ${ }^{4}$.

O número de participantes variou (de 9 a 16) a cada encontro, em função da flexibilidade do horário de chegada das crianças à escola. Os encontros tiveram a duração média de duas horas cada. A cada encontro era feita a leitura de um livro pela professora; enquanto ela lia, a pesquisadora movia os fantoches dos personagens do livro, conforme eles apareciam na história. Após o término da leitura, as crianças eram divididas em dois grupos com um número aproximado de 6 participantes, facilitando assim o diálogo e a participação de todos. A pesquisadora, então, solicitava às crianças que recontassem individualmente a história, em um primeiro momento sem apresentar-lhes nenhum fantoche. Esgotadas as possibilidades de narrativas sem os fantoches, os mesmos eram disponibilizados e novamente cada criança tinha a oportunidade de construir individualmente sua narrativa, fazendo ou não o uso dos fantoches, a seu critério. $\mathrm{O}$ mesmo procedimento se repetia com o segundo grupo.

A maioria das crianças mostrou-se bastante interessada em participar das atividades, solicitando à pesquisadora que voltasse mais vezes e levasse os fantoches para eles usarem. Todos os encontros foram gravados em vídeo e transcritos na íntegra. Posteriormente, foram feitas análises qualitativas sobre o material. A seguir serão apresentados os resultados, com foco no uso que as crianças fizeram dos fantoches.

4. A aprovação do projeto pelo Comitê de Ética em Pesquisa com Seres Humanos foi exarada no protocolo número 2.303.349 
As narrativas produzidas pelas crianças podem revelar, entre outros fatores, $\mathrm{o}$ que a história narrada representa para elas, e podem ser analisadas de diversas maneiras. Para compararmos as narrativas feitas com e sem os fantoches, observamos a estrutura das narrativas produzidas, verificando sua extensão; a manutenção e a criação de personagens; o grau de aproximação com a história real; a coerência dos relatos com a ordem temporal e causal; a relação entre os eventos narrados que precisam estar conectados entre si; a completude dos episódios (completos ou incompletos). Essas observações, embora não explícitas nas análises, serviram-nos de suporte para que pudéssemos examinar as produções das crianças, sem desconsiderar, é claro, a teoria Histórico-cultural que sustenta esta pesquisa.

\section{Resultados}

Como os fantoches podem contribuir para a construção de narrativas por crianças pequenas? Veremos a seguir como eles influenciaram em vários aspectos a narrativa das crianças. Primeiramente, observaremos que, de maneira geral, houve um aumento na motivação das crianças para narrar quando os fantoches eram disponibilizados a elas, em comparação aos momentos de narrativas sem os fantoches, conforme ilustramos a seguir no encontro em que foi utilizado o livro Não tenha medo Alfredo!s:

Pesquisadora: Vem Iasmin, o que você lembra?

Iasmin: Não sei.

Pesquisadora: Não sabe? Não acredito... Não quer contar nada?

Iasmin: Não.

$[\ldots]$

Pesquisadora: Vem Iasmin.

Iasmin: [pega o Alfredo e o polvo] E aí, ele ficou sozinho. E aí, ele estava com medo de tudo. Ele tinha medo de que as patas deles se enroscassem.

Iasmin: E aí, ele, o Alfredo estava com medo de se perder. E depois, os amigos dele falou que o Alfredo não tinha medo mais...

5. Esse livro fala da história de um camarãozinho que não brincava com os amigos porque tinha medo de tudo e os amigos sempre diziam: “Não tenha medo, Alfredo!”. Até que um dia ninguém mais o chamou para brincar e ele ficou sozinho. Então percebeu que ninguém tinha se perdido, sido esmagado ou se enroscado... Na verdade, todos só estavam se divertindo e então ele começou a brincar também. 
A narrativa prossegue enquanto Iasmin vai trocando e manipulando os fantoches. Ela narra mais trinta frases somente nesse episódio. Outras crianças, assim como Iasmin, também agiram dessa maneira em vários momentos, demonstrando a importância do uso dos signos externos para o desenrolar de suas narrativas.

Na medida em que são propiciados para as crianças contatos com os objetos culturais - nesse caso os fantoches -, todo o seu sistema psíquico é colocado em funcionamento de outro(s) modo(s) e em transformação: pensamento, fala, memória, imaginação... As crianças vão relembrando e reelaborando os fatos, e esse movimento afeta seu desejo de narrar e a extensão das narrativas. [...] "nós, seres humanos, não apenas reproduzimos, mas também criamos novas imagens e ações, combinando e reelaborando dados da experiência anterior" (SACCOMANI, 2014, p. 63), trazendo à tona inclusive detalhes que ficaram ausentes sem o uso dos fantoches. Veremos mais um exemplo, observado no dia em que foi utilizado o livro Quer brincar de pique-esconde? ${ }^{6}$

Helena, sem os fantoches, começa a narrar, mas sua memória limita-se a pequenos trechos da história. Então ela diz:

Helena: Eu lembro que... Tia eu não consigo lembrar...

Após a disponibilização dos fantoches, Helena pega o fantoche do macaco, da girafa e do coelho e começa a narrar:

Helena: Eu lembro que a girafa, ela deixou a cabeça de fora.

Pesquisadora: E o que mais?

Helena: E eu lembro que o macaco deixou o rabo de fora...

A narrativa prossegue nessa estrutura, dos animais se esconderem, deixarem algo para fora e serem encontrados. Além de citar os animais existentes na história, ela também inclui uma lagarta e um rato, de maneira coerente com o enredo:

Helena: E a lagarta, ela deixou seu olho de fora.

$[\ldots]$

Helena: E o ratinho, tão lindo, tão gentil. Ele até que... Ele deixou o nariz de fora.

6. A história fala de diversos animais que estão brincando de esconde-esconde e esquecem alguma parte do corpo para fora, sendo rapidamente localizados pelo macaco que os procura. $\mathrm{O}$ único que não é encontrado é o camaleão, que vence a brincadeira por ser o mestre do disfarce. 
Helena mantem essa estrutura em sua narrativa, até pegar o fantoche do camaleão e concluir a história.

Helena: $\mathrm{O}$ camaleão ele foi o vencedor. E todos perderam.

Percebe-se que após a disponibilização dos fantoches, Helena inclui diversos personagens, utilizando os fantoches como suportes da memória mediada, função esta que ainda está em formação. Vale destacar também o fato de Helena ter atribuído características física e psicológica a um dos personagens, ao dizer: "e o ratinho, tão lindo, tão gentil....' Isso demonstra uma sofisticação na sua fala e no seu pensamento, ou seja, no seu desenvolvimento psíquico como um todo, desenvolvimento promovido pela mediação dos signos.

Chamamos signos aos estímulos-meio artificiais introduzidos pelo homem na situação psicológica, que cumprem a função de autoestimulação, agregando a este termo um sentido mais amplo e, ao mesmo tempo, mais exato do que se dá, habitualmente, a essa palavra. De acordo com essa definição, todo estímulo condicional criado pelo homem artificialmente e que se utiliza como meio para dominar a conduta - própria ou alheia - é um signo. (VIGOTSKI, 1995, p. 83).

Utilizando como base a mesma história e os mesmos fantoches propostos a Helena, observaremos a seguir a narrativa de Guilherme, que cria um vilão e atribui a ele as características de malvado e de não gostar das pessoas. Por meio de novas recombinações, ele faz surgir o inusitado, reforçando a tese de Vigotski (2009), que afirma que, ao imaginar, combinar, reelaborar experiências, o homem cria o novo, modifica o seu presente e se volta para o futuro.

Guilherme: Eu lembro daquele macaco que queria procurar aquele que estava fora da toca, e daquele que era maior que todos e que não gostava das pessoas, ele era muito malvado. Pesquisadora: Quem era malvado?

Guilherme: Aquele verdão.

Pesquisadora: Quem era o verdão?

Guilherme: Aquele do fantoche.

Guilherme: Tia, você me dá o verdão?

Pesquisadora: Eu vou colocar os fantoches aqui.

Guilherme: É esse [pega o camaleão]. 
Guilherme: Esse é o verdão que não gostava de pessoas. Ele pegava as pessoas porque ele era muito malvado.

Guilherme: [olha para todos os fantoches e começa a falar sobre eles] O coelho fez errado porque ele deixou a cauda dele para fora e o gambá e a raposa. O elefante deixou sua tromba de fora. E depois o rato...

Guilherme prossegue sua narrativa falando dos animais e do que eles esqueceram para fora, depois a conclui:

Guilherme: $\mathrm{O}$ macaco achou todo mundo, mas ele não achou...

Pesquisadora: Quem ele não achou?

Guilherme: Esse daqui [mostra o fantoche do camaleão, que estava o tempo todo em sua mão].

Pesquisadora: Ahhh! E aí o que aconteceu?

Guilherme: Ele não achou esse, porque estava do outro lado do rio. E, não conseguiu encontrar porque caiu no rio.

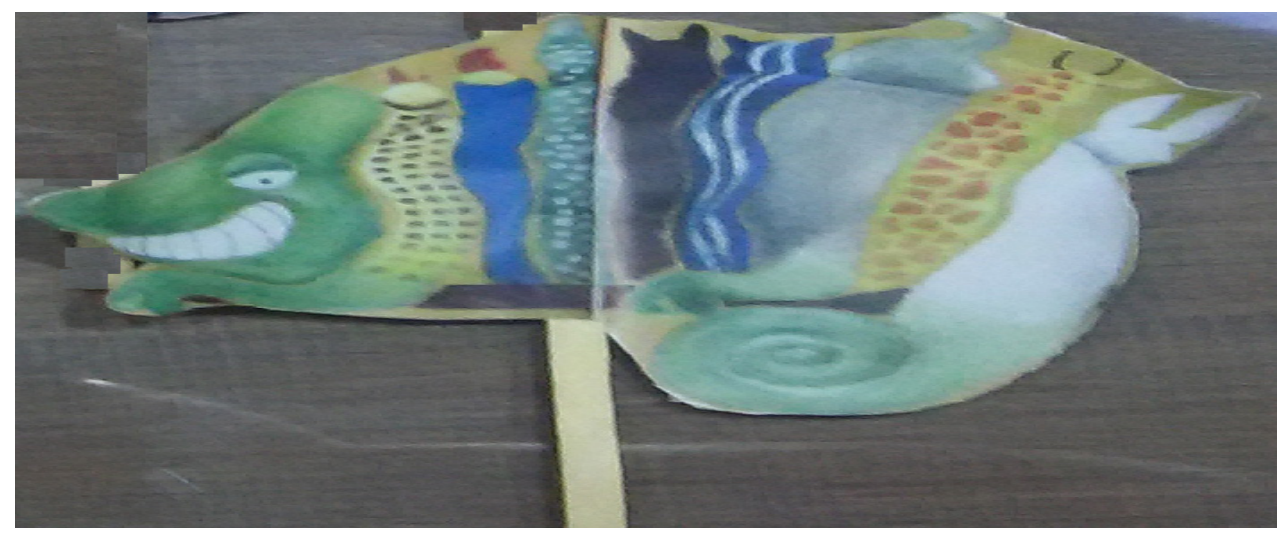

Figura 1 - Fantoche do camaleão - Fonte: Arquivo pessoal da pesquisadora

Guilherme, apoiado no fantoche, cria um novo personagem, dando um nome a ele, definindo sua personalidade, criando um novo cenário e incluindo todos esses tópicos no enredo da história, apresentando sequência lógica e concluindo-a. Essas transformações no enredo podem ter sido influenciadas pela imagem do camaleão, sobretudo pelo sorriso e o olhar, que nos parecem ambíguos, podendo ser interpretados como 
de alegria e esperteza (o que seria mais coerente com o texto), mas, também realçando certos traços presentes nesses elementos, como sendo de alguém malvado ou ardiloso.

Os fantoches têm papel fundamental na criação da nova versão da história de Guilherme. Para ele, assim como para as demais crianças, dispor de um objeto material, visual e/ou manipulável para servir de suporte e legitimação da história a ser narrada faz diferença naquilo que é produzido.

As crianças demonstram tendência em querer interpretar a imagem dos fantoches, o que causa, em alguns momentos, conflitos entre o perceptível visualmente e os sentidos em circulação, conforme observaremos no encontro em que o livro utilizado foi A Raposa e as Uvas'. Um fantoche da personagem principal da história, a raposa, foi entregue para cada criança assim que pareceram findar as possibilidades de construção de narrativas sem o uso dos instrumentos mediadores. Ao recebê-lo, as crianças começaram a falar sobre ele:

Guilherme: O dente da raposa é verde, né? [fala olhando para o fantoche].

Marcos: Verde.

Guilherme: Tia, o dente da raposa é verde?

Pesquisadora: Não sei se é verde, você acha que é verde?

Geovana: Os olhos dela são verdes [olha para o fantoche].

A discussão continua... No início desse encontro, ocorrido ainda na fase inicial da pesquisa, as crianças fazem uso dos fantoches para falar das características físicas da raposa, atentas, de modo especial, ao plano da percepção visual.

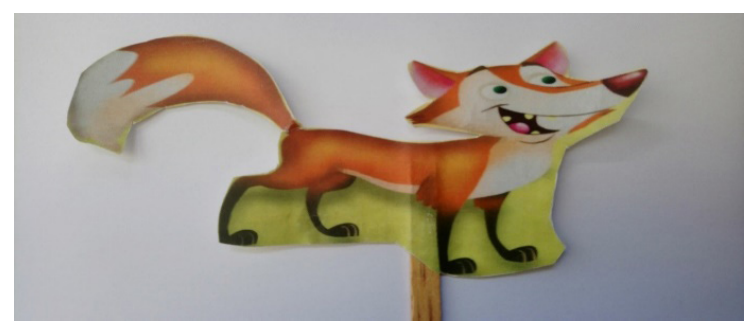

Figura 2 - Fantoche da raposa - Fonte: Arquivo pessoal da pesquisadora

7. A história fala de uma raposa que avistou uvas que pareciam estar deliciosas; tentou pegá-las de toda maneira, e, como não conseguiu, preferiu dizer que não as queria, porque deveriam estar verdes e azedas. Trabalhando em equipe, um ratinho e duas borboletas conseguiram pegar as uvas, que estavam docinhas. 
No decorrer desse mesmo episódio, as crianças também utilizaram os fantoches para a interpretação de questões cruciais da história, como podemos acompanhar a seguir:

Pesquisadora: $\mathrm{O}$ que a raposa queria fazer na história?

Marcos: Ela não queria comer nem uva.

Pesquisadora: Ela não queria comer a uva. Você tem certeza de que ela não queria?

Marcos: Tem que ver, né.

Pesquisadora: Ela queria.

Marcos: Tem que ver, porque ela falou que estava verde.

$[\ldots]$

Guilherme: Tia, nessa história a dona uva é azul [fala apontando para a uva que está no fantoche do rato na mão da pesquisadora].

Pesquisadora: [olha para o fantoche] Ah é, a uva é azul.

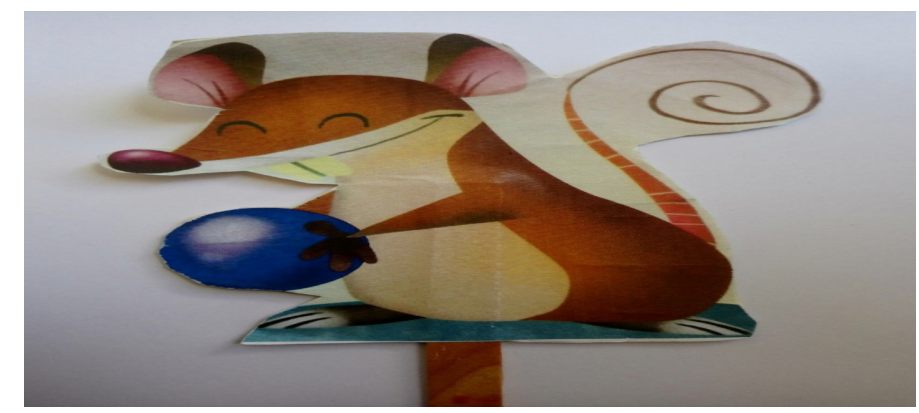

Figura 3 - Fantoche do ratinho com a uva azul - Fonte: Arquivo pessoal da pesquisadora

Percebe-se nesse episódio alguns dilemas, sendo um deles o fato de o dente da raposa ser verde no fantoche, o que contradiz informações que as crianças trazem da realidade, em que os dentes, em geral, são brancos. Outro é o fato de a uva ser azul no fantoche e qualificada como verde, na história, com a frase "com certeza, estão todas verdes e azedas", dita pela raposa. Isso gera um conflito entre o que se diz e o que se vê na história, mostrando a importância dada para a percepção visual e a aplicação de critérios de verossimilhança. Essa dupla informação sobre a cor da uva causa um conflito crucial para a interpretação da história, entre a raposa querer ou não comer a uva... Ou seja, a uva é verde e azeda ou azul e docinha? 
A dúvida sobre a cor da uva mostra o movimento que as crianças fazem entre o percebido visualmente e as interpretações e os sentidos que estão em circulação na história e nas falas dos participantes. Guilherme, ao dizer: "mas olha, no fantoche a uva é azul”, está buscando atribuir um sentido para a história, apoiado na materialidade do fantoche, usando esse instrumento para sustentar sua narrativa. Já quando Marcos diz: "tem que ver, porque ela falou que estava verde", embora ele fique na dúvida, demonstra um certo grau de desprendimento do empírico, deixando de privilegiar o perceptível e passando a privilegiar os sentidos em circulação. É pertinente relembrar nesse ponto a tese de Vigotski, que afirma que os significados primeiramente circulam entre as pessoas, e somente depois cada sujeito se apropria deles, ou seja, são primeiro externos, depois internos.

Algumas crianças, embora bem pequenas, demonstraram grande habilidade em narrar com o apoio dos fantoches e conseguiram assumir diferentes papéis, diversas vozes, ora como narrador, ora como personagens; também conseguiram construir diálogos entre os personagens, conforme pode ser visto no excerto a seguir, no qual o livro utilizado foi Qual é a cor do amor?

Helena (como se fosse o narrador): O elefantinho ele estava andando [pega o elefante e o faz andar na mesa]. Ele viu todas aquelas cores e ele pensou:

Helena (elefante): Qual que é a cor do amor?

Helena (narrador): Ele falou assim:

Helena (elefante): Será que é azul? [troca o elefante pelo gambá azul].

Helena (gambá): Não pode ser azul. Pode ser vermelho [devolve o gambá].

Helena (elefante): Qual que é a cor do amor? Será que é verde?

Helena (narrador): Depois a árvore falou [pega a árvore]:

Helena (árvore): Não pode ser. Deve ser amarela [devolve a árvore].

Helena (elefante): Qual que é a cor do amor?

Helena (narrador): Então ele falou:

Helena (elefante): Rosa. [pega o flamingo].

Helena (flamingo): Não pode ser cor de rosa, pode ser laranja [devolve o fantoche].

8. Essa história fala de um elefantinho que queria descobrir qual é a cor do amor e sai perguntando para todos os animais que encontra. Mas nenhum dos interlocutores sabe responder; só sabem dizer que não pode ser uma certa cor, porque ela já pertence a algo. Até que ele pergunta para sua mãe e ela diz que o amor é formado por todas as cores. 
A narrativa prossegue nessa estrutura do elefante perguntar a cor do amor aos animais com quem ele vai se encontrando, até que, desanimado, vai conversar com a sua mãe.

Helena (narrador): Então a mãe dele falou: [pega mais um elefante].

Helena (mãe do elefante): Sabe qual que era a cor do amor meu filhinho? Sabe qual é? Helena coloca um elefante de frente para o outro, como se estivessem conversando. Helena (mãe do elefante): São todas as cores! Entendeu? Todas as outras cores se tornam a cor do amor.

Em sua narrativa, em alguns momentos Helena assume o papel de narrador, em outros assume o papel dos personagens da história, dando voz aos animais que, na maioria das vezes, estão em suas mãos, sendo representados pelos fantoches. Ela faz também uma ligação entre a possível cor do amor e a cor do personagem que está manipulando, como, por exemplo, indicando a cor azul quando pega o gambá, verde quando pega a árvore e rosa quando escolhe o flamingo. Mostra, assim, claramente o apoio em um signo externo (fantoche), que serve de suporte para sua narrativa e imaginação. Vale destacar o momento em que ela coloca os fantoches frente a frente e promove um discurso direto entre eles, movimentando-os e mudando seu próprio tom de voz, para deixar claro que são dois personagens diferentes falando.

Thiago, nesse mesmo encontro, também assume os papéis de narrador e de diversos personagens, conforme pode ser visto a seguir:

Thiago (como se fosse o narrador): O elefantinho e o jacaré [pega os dois fantoches]. Thiago (jacaré): Que foi Sr. Elefante?

Thiago (elefante): Qual é a cor do coração?

Thiago (jacaré): É vermelho. [troca o jacaré pelo tigre].

Thiago (elefante): Ei, qual é a cor da... A cor... do coração?

Thiago (tigre): Ele será branco. [troca o tigre pelo macaco].

Thiago (elefante): Ô macaco. Ei, ei..

Thiago (macaco): Que foi?

Thiago (elefante): Eu preciso de uma ajuda [...]

A narrativa prossegue nessa mesma estrutura. Percebe-se que além de assumir o papel de narrador e dos personagens, Thiago acrescenta algumas expressões que 
dão mais vida à história, como por exemplo, "que foi Sr. Elefante?”; “ô macaco. Ei, ei...,. Essa maneira de narrar evidencia uma demanda do seu funcionamento imaginativo, dando singularidade à sua produção. Isso demonstra a materialidade afetando sua capacidade de narrar, viabilizada por uma atividade que demanda o funcionamento das funções psíquicas e que ensina possibilidades de utilização de recursos materiais. Demonstra, portanto, vias de desenvolvimento que atividades repetitivas e mecânicas não demandariam; por isso são tão importantes a literatura, essa experiência com os fantoches e a oportunidade de se construir narrativas:

A literatura infantil pode desempenhar um papel ainda mais positivo quando o uso do texto pode ser diversificado, ou seja, quando cada criança é estimulada a construir suas significações entretecidas com o texto, a partir de suas experiências, incorporando-as em seu modo de pensar, sentir e agir (BRITO; ROCHA, 2016. p. 48).

No encontro em que a leitura do livro Quer brincar de pique-esconde foi apoiada nos fantoches, três crianças realizam uma dupla dramatização, incorporando os personagens, conforme veremos a seguir:

Tadeu: [pega dois fantoches de macacos] Dois macaquinhos aqui ó...

Tadeu faz barulho e gestos de macaco, ao mesmo tempo em que movimenta os fantoches. Leonardo se levanta e começa a imitá-lo.

Iasmin: Tia, olha o que o meu macaco faz [gesticula, imitando um macaco também]. Pesquisadora: Faz assim?!

Tadeu: [pega a arara] A arara fazia assim ó... [faz como se o fantoche estivesse voando e o troca pela girafa].

Tadeu: A girafa. Ela faz assim ó... [ele move o fantoche, como se estivesse andando sobre a mesa e depois o troca pela cobra]. E a cobra, fez assim ó: ssssss [ele arrasta o fantoche na mesa e faz barulho de cobra, depois o devolve].

A narrativa segue com Tadeu incorporando os animais e movendo os fantoches, fazendo com que o camaleão, por exemplo, ataque os colegas, emitindo um barulho alto e gesticulando. Em outro momento, ele pega um fantoche de coelho, finge que está dando pequenos saltos na mesa, depois se levanta e sai pulando pela sala, enquanto narra o que o coelho fazia. 
Conforme pode ser observado, os fantoches afetam em especial a capacidade imaginativa de Tadeu, que incorporou os personagens e imitou sons e movimentos dos animais que estavam sendo manipulados por ele. Ele também incrementou sua narrativa pela linguagem gestual, ao fazer com que os fantoches andassem pela mesa, voassem, rastejassem, como se fossem reais. Essas ações extrapolam as que seriam pertinentes e/ou necessárias à história a ser narrada, originam-se daquilo que as crianças sabem sobre os comportamentos mais típicos dos animais. Também são ações simbólicas, bastante próximas das ações de personagens projetados, analisados por Góes (2000) como uma das possibilidades de dramatização nas brincadeiras de faz-de-conta. As crianças transitam entre a instrução (dada pela pesquisadora e assumida por eles próprios) de representar o que os personagens fazem na história e de representar o que os animais fazem em contextos gerais, inspirando-se em conhecimentos gerais que têm sobre os mesmos, advindos de múltiplas circunstâncias.

Segundo Vigotski (2014), a dramatização é uma importante forma de manifestação da imaginação criativa na criança: "tudo o que pensa e sente, a criança quer concretizar em imagens vivas e em ações” (VIGOTSKI, 2014, p. 87). Para o autor, a dramatização possibilita à criança transitar entre imagens, situações, afetos e conhecimentos diversos entre si.

As análises nos permitiram identificar que os fantoches, além de aumentar a motivação das crianças para recontar as histórias, afetaram, positivamente, a estrutura das narrativas produzidas: tornaram-nas mais extensas, ajudaram a manter o nível de coerência temporal e causal e a deixá-las mais completas. As crianças utilizaram os fantoches para sustentar os enredos, em alguns momentos narrando mais coisas pela linguagem gestual (ou apenas pela linguagem gestual); incluíram e criaram personagens, na maioria das vezes de maneira coerente com o argumento central das histórias; experimentaram diferentes vozes e assumiram diferentes papéis, ora de narrador, ora de personagens; construíram diálogos entre personagens; apontaram suas características físicas e psicológicas. Ou seja, há evidências de que a introdução e uso destes recursos semióticos permitem a produção de formas narrativas mais complexas e colocam em funcionamento todo o conjunto de funções psíquicas.

\section{CONSIDERAÇõES FINAIS}

Antes de finalizarmos o artigo, faremos algumas considerações sobre a literatura, pois, se mostramos modos pelos quais os fantoches afetaram as possibilidades 
de narrar das crianças, não podemos minimizar a importância dos livros e das leituras feitas pela professora para a turma.

Conforme expusemos no tópico introdutório desse artigo, no trabalho feito com a literatura infantil tende a predominar o uso dos livros de histórias como um instrumento para ensinar outras coisas, num processo que tem sido chamado de pedagogização. Nesse caso, as narrativas ficam a serviço da alfabetização, da matemática, das lições de moral. Não foi essa a nossa perspectiva: nos encontros com as crianças procuramos colocar em primeiro plano as histórias. Assim, as escolhas sobre quais livros apresentar e como fazê-lo não foram aleatórias e tinham como critério o maior potencial para envolvê-las na relação com a literatura.

Certamente, nunca é possível controlar todo o processo e nem almejávamos isso, já que, quando se trata de produções no campo da criação e imaginação é imprescindível, sempre, deixar margem para o imprevisto, o inaudito, o deleite. Sendo assim, os múltiplos modos como as crianças expressam seus interesses e sua imersão nas histórias são heterogêneos e merecem ser observados e respeitados, mas também desafiados. Afinal, "onde o meio não cria problemas correspondentes, não apresenta novas exigências, não motiva nem estimula com novos objetivos o desenvolvimento do intelecto, [...] [ele] não atinge as formas superiores ou chega a elas com extremo atraso" (VIGOTSKI, 2009, p. 171). E as crianças, mesmo bastante pequenas, mostraram-se capazes de darem novos passos nas suas relações com a literatura e na sua capacidade de produzirem narrativas.

\section{REFERÊNCIAS}

ABRANTES, A. A. A educação escolar e a promoção do desenvolvimento do pensamento: a mediação da literatura infantil. Tese de Doutorado em Educação, Campinas, SP: Universidade Estadual de Campinas, 248 p., 2011.

ABRANTES, A. A. Educação escolar e desenvolvimento humano: a literatura no contexto da Educação Infantil. In: MARSIGLIA, A. C. G. Infância e pedagogia histórico-crítica. Campinas, SP: Autores Associados, 2013.

BRITO, L. E.; ROCHA, M. S. P. M. L. Literatura na Educação Infantil: modos de trabalho com textos e possibilidades do desenvolvimento da capacidade criativa. Revista Teoria \& Prática, Campinas - SP, v. 34, n. 68, p. 45-64, 2016.

BRUNER, J. The narrative construction of reality. Critical Inquiry, 17, 1991.

COSTA, M. M.; RAMOS, F. B.; PANOZZO, N. S. P. Educação Infantil: literatura como espaço de fruição. Revista Signo, UNISC, Santa Cruz do Sul, v. 32, n. 53, p. 128-140, 2007. Disponível em: https://online.unisc.br/seer/index.php/signo/article/view/82/182. Acesso em: 30 dez. 2018 
GERALDI, J. W. O texto na sala de aula. 4. ed. São Paulo: Ed. Ática, 2006.

GÓES, M. C. R. O jogo imaginário na infância: a linguagem e a criação de personagens. In: REUNIÃO ANUAL DA ANPED, 23., 2000, Caxambu, MG. Anais... Caxambu, MG, 2000.

KIRCHOF, E. R.; SILVEIRA, R. M. H. Contação de história: uma análise da escolha de histórias em um recorte de experiências gaúchas. Revista Conjectura: filosofia e educação, UCS, Caxias do Sul, RS: Educs, v. 14, n. 2, maio/ago. 2009.

MACHADO, H. C. "Hoje posso ser eu tia?": Leitura fruição pela voz e mãos de crianças da Educação Infantil Dissertação de Mestrado - Pontifícia Universidade Católica de Campinas, Campinas, SP, 2017.

MORTATTI, M. R. L. Na história do ensino da literatura no Brasil: problemas e possibilidades para o século XXI. Educar em Revista, Editora UFPR, Curitiba, n. 52, p. 23-43, abr./jun. 2014.

SACCONAMI, M. C. S. A criatividade na arte e na Educação Escolar: uma contribuição à pedagogia histórico-crítica à luz de Georg Lukács e Lev Vigotski. Dissertação de Mestrado - Faculdade de Ciências e Letras, Universidade Estadual Paulista (UNESP), Araraquara, SP, 2014

SILVA, J. P.; URT, S. C. O valor da arte literária na construção da aprendizagem da criança. Revista Nuances: estudos sobre Educação, Presidente Prudente - SP, v. 27, n. 1, p. 225-246, jan./abr. 2016 VIGOTSKI, L. S. A Construção do Pensamento e da Linguagem. São Paulo: Martins Fontes, 2009. VIGOTSKI, L. S. Imaginação e criatividade na infância. São Paulo: Martins Fontes, 2014 VIGOTSKI, L. S.; LEONTIEV, A. N.; LURIA, A. R. Linguagem, desenvolvimento e aprendizagem.

São Paulo: Ícone, 2012.

VYGOTSKI, L. S. Obras Escogidas. Volume III. Madrid: Visor. 1995

\section{SOBRE AS AUTORAS}

Marcela A. Moreira Araujo é graduada em Administração (Centro Universitário de Jaguariúna), tem mestrado em Educação (Pontifícia Universidade Católica de Campinas). Tem experiência na área de recursos humanos, gestão de projetos e educação infantil, com pesquisas nos seguintes temas: Educação Infantil, Formação de Professores; Práticas pedagógicas. É bolsista CAPES.

E-mail: mamoreyra_@hotmail.com.

ORCID: https://orcid.org/oooo-ooo2-7329-1297

Maria Silvia Pinto de Moura Librandi da Rocha é graduada em Psicologia (PUC-Campinas), tem Mestrado em Educação (Universidade Estadual de Campinas) e tem Doutorado em Educação (Universidade Estadual de Campinas). É professora/ pesquisadora Programa de Pós-graduação da PUCCampinas. Tem experiência na área de Educação, com pesquisa nos seguintes 
temas: Teoria Histórico-cultural, Funções Psicológicas Mediadas, Literatura Infantil, Educação Infantil.

E-mail: silrocha@uol.com.br.

ORCID: http://orcid.org/oooo-ooo2-60o1-1292.

Texto aprovado em 18/10/2021. 